\title{
Distinção e Aspectos Jurídicos das Águas Minerais e Subterrâneas no Brasil
}

\author{
Patrícia Borba Vilar Guimarães \\ Departamento de Direito Público, UFRN \\ patriciaborba@ig.com.br
}

Márcia Maria Rios Ribeiro

Unidade Acadêmica de Engenharia Civil, UFCG

mm-ribeiro@uol.com.br

Recebido: 14/07/09 - revisado: 19/01/10 - aceito: 16/04/12

\begin{abstract}
RESUMO
Esse trabalho realiza uma compilação conceitual acerca da caracterização e distinção dos aspectos jurídicos e físicos das águas minerais e das águas subterrâneas, com o objetivo de explorar os pontos controvertidos dessa distinção, a fim de orientar o processo da gestão integrada de recursos hídricos sob o ponto de vista institucional. Realizou-se uma pesquisa bibliográfica e documental acerca dos principais textos legais nacionais que propiciam essa distinção, bem como da delimitação e abrangência dos direitos minerários e do direito das águas, como forma de oferecer contributos à eficiente institucionalização do processo de gestão do bem jurídico água no contexto brasileiro. Aspectos das competências dos respectivos órgãos de gestão são levantados verificando-se os possíveis pontos de conflito e convergência.
\end{abstract}

Palavras-chave: Direito de águas, águas minerais, águas subterrâneas.

\section{INTRODUÇÃO}

Este trabalho visa a analisar aspectos legais e institucionais que permitem distinguir características da gestão de águas subterrâneas e das águas minerais, que, apesar de aparentemente provenientes da mesma fonte de exploração comum, possuem regimes diferenciados de caracterização jurídica, o que afetará essencialmente a natureza da sua gestão.

Procurou-se compilar conceitos acerca da caracterização e distinção dos aspectos jurídicos e físicos das águas minerais e das águas subterrâneas, com o objetivo de explorar os pontos controvertidos dessa distinção, a fim de orientar o processo da gestão integrada dos recursos hídricos sob o ponto de vista institucional.

Realizou-se uma pesquisa bibliográfica e documental acerca dos principais textos legais nacionais que propiciam essa distinção, bem como da delimitação e abrangência dos direitos minerários e do direito das águas, como forma de oferecer contributos à eficiente institucionalização do processo de gestão do bem jurídico água no contexto brasileiro.

\section{DISTINÇÃO E CARACTERIZAÇÃO JURÍDICA DAS ÁGUAS DOCES NO BRASIL}

\section{Linhas gerais da gestão de águas doces}

No que se refere à legislação infraconstitucional específica sobre águas a Lei nº 9.433/97 regulamenta o artigo 21, inciso XIX, da Constituição Federal, estabelecendo a competência da União para instituir a Política Nacional de Recursos Hídricos (PNRH) e o Sistema Nacional de Gerenciamento dos Recursos Hídricos (SINGREH).

A Lei no 9.433, de janeiro de 1997, institui a água como sendo um recurso natural limitado e dotado de valor econômico. Esse diploma legal emergiu em período em que os instrumentos econômicos tiveram destaque ampliado em relação a alternativas de controle e regulação. A referida lei baseia-se nos seguintes fundamentos, entre outros: "a água é um bem de domínio público; a água é um recurso natural limitado, dotado de valor econômico; a gestão dos recursos hídricos deve sempre proporcionar o uso múltiplo das águas;" (art. 1ํ) (Brasil, 1997).

No aspecto da fundamentação de uma política que inclui elementos de prevenção de danos 
futuros, encontra-se referência aos objetivos da PNRH, como: "assegurar à atual e às futuras gerações a necessária disponibilidade de água, em padrões de qualidade adequados aos respectivos usos; a utilização racional e integrada dos recursos hídricos, incluindo o transporte aquaviário, com vistas ao desenvolvimento sustentável; a prevenção e a defesa contra eventos hidrológicos críticos de origem natural ou decorrentes do uso inadequado dos recursos naturais.” (art. $2^{\circ}$ ) (Idem). Assim, dispõe a legislação federal que disciplina a gestão dos recursos hídricos, encabeçada pela Lei n 9.433/97 (Brasil, 1997):

Art. 30. Na implementação da Política Nacional de Recursos Hídricos, cabe aos Poderes Executivos Estaduais e do Distrito Federal, na sua esfera de competência:

I. outorgar os direitos de uso de recursos hídricos e regulamentar e fiscalizar os seus $u^{-}$ sos;

II. realizar o controle técnico das obras de oferta hídrica;

III. implantar e gerir o Sistema de Informações sobre Recursos Hídricos, em âmbito estadual e do Distrito Federal;

IV. promover a integração da gestão de recursos hídricos com a gestão ambiental.

A legislação reguladora do setor de águas é fundamental para o desenvolvimento estrutural do país, o que justifica o aprofundamento teórico das questões ligadas ao meio-ambiente e à gestão deste recurso natural. Residem nestas considerações, a possibilidade de o leque de aspectos abrangido pelo uso da água e seu disciplinamento, em consonância com o princípio legal que determina o seu uso múltiplo - dessedentação, saneamento, consumo humano, produção de bens, etc. - reclamar uma análise focada inicialmente nos aspectos legais, especificamente à configuração da água como bem público e como recurso natural limitado, de valor econômico (Brasil, 1997). A lei não faz distinções no tocante à gestão de águas doces superficiais e subterrâneas.

\section{A aquisição de direitos sobre a exploração de águas subterrâneas}

A resolução do Conselho Nacional de Recursos Hídricos - CNRH - nº 15/2001 assim define as águas subterrâneas, águas meteóricas, aquífero e corpo hídrico subterrâneo:

Art. $1^{\circ}$ Para efeito desta resolução consideram-se:
I. Águas Subterrâneas - as águas que ocorrem naturalmente ou artificialmente no subsolo;

II. Águas Meteóricas - as águas encontradas na atmosfera em quaisquer de seus estados físi$\cos$;

III. Aqüífero - corpo hidrogeológico com capacidade de acumular e transmitir água através dos seus poros, fissuras ou espaços resultantes da dissolução e carreamento de materiais rochosos;

IV. Corpo Hídrico Subterrâneo - volume de água armazenado no subsolo. (CNRH, 2001a).

Entende-se, entretanto, como definição de água subterrânea mais completa, aquela de Albuquerque e Rêgo (1998) e de Albuquerque (2007): "água subterrânea é aquela que ocorre e que circula em profundidade preenchendo poros de naturezas diversas (vazios entre grãos, fraturas, falhas e fissuras abertas, cavidades cársticas, juntas entre camadas ou entre colunas de rochas vulcânicas, etc.) e/ou que aflora e circula em superfície formando lagos, lagoas ou constituindo o escoamento de base da rede hidrográfica superficial'.

As águas minerais, por sua vez, são aquelas que em geral atingiram profundidades maiores que, por isto, se enriqueceram em sais, adquirindo novas características físico-químicas, como, por exemplo, $\mathrm{pH}$ mais alcalino e temperatura maior. Logo, as águas minerais, por sua composição química ou características físico-químicas são diferenciadas, uma vez que são enriquecidas em sais obtidos das rochas e sedimentos por onde percolaram ao longo do tempo. Desse modo, a água que possui determinadas propriedades físico-químicas que permitem identificá-la como mineral é tratada pelo direito como um minério, e sua exploração está sujeita ao controle ambiental em função das peculiaridades da exploração, como assim está qualquer modalidade de água subterrânea, em razão de deterem as características de afetação de aquíferos, que podem sofrer prejuízos com a sobre-exploração.

Segundo o Código de Águas do Brasil em seu artigo $1^{\circ}$, águas minerais naturais "são aquelas provenientes de fontes naturais ou de fontes artificialmente captadas que possuam composição química ou propriedades físicas ou físico-químicas distintas das águas comuns, com características que lhes confiram uma ação medicamentosa" (Brasil, 1945). Apesar de a Constituição Federal manter como bens da União os recursos minerais, no artigo 23, essa competência é dividida entre a União, os Estados e o Distrito Federal (Brasil, 1988). 
Nos termos da lei brasileira, a aquisição de direitos minerários para o particular que deseje realizar a exploração de águas minerais se dá mediante a emissão de uma Portaria de Lavra pelo Departamento Nacional de Produção Mineral (DNPM), com base no Código de Mineração (Brasil, 1967), no Código de Águas Minerais (Brasil, 1945) e nas Portarias 222/1997 e 231/1998 do DNPM. A legislação também exige o licenciamento ambiental, ao encargo dos órgãos ambientais estaduais. A Portaria de Lavra é o documento que habilita ao particular para a exploração dos recursos naturais dessa natureza, através da cessão de direitos minerários.

Para as águas subterrâneas não classificadas como minerais, o processo de exploração deve ser precedido pela outorga do direito de uso, e demais instrumentos consentâneos de gestão, tratados mais adiante neste texto.

\section{O processo de obtenção da cessão de lavra no DNPM}

Segundo o artigo 10 do Código de Águas Minerais (Brasil, 1945), "Art. 10 - A lavra de uma fonte de água mineral, termal, gasosa, potável de mesa ou destinada a fins balneários, será solicitada ao Ministro das Minas e Energia", através do DNPM, que será o cessionário dos direitos de lavra. Com a edição da Resolução no 76 do CNRH (2007), o processo autorizativo deve ser complementado nos seguintes termos:

Art. 10. Após a concessão da Portaria de Lavra, o órgão gestor de recursos minerais encaminhará ao órgão gestor de recurso hídrico competente, no mínimo, as seguintes informações:

I. projeto do sistema de captação;

II. estudos analíticos da água mineral, termal, gasosa, potável de mesa ou destinada a fins balneários previstos no Decreto-Lei $\mathrm{n}^{\text {o }}$ 7.841, de 1945;

III. localização geográfica dos poços ou fontes;

IV. balanço hídrico do empreendimento, ensaio de bombeamento dos poços e sua interpretação, quando houver;

V. vazão constante no relatório final de pesquisa aprovado;

VI. área ou perímetro de proteção da fonte.

O mesmo ocorre no momento da extinção dos direitos minerários, quando "Art. 11. Em caso de indeferimento do requerimento ou extinção do título de pesquisa ou de lavra de água mineral, termal, gasosa, potável de mesa ou destinada a fins balneários, por qualquer motivo, o órgão gestor de recursos minerais deverá comunicar o fato ao órgão gestor de recursos hídricos.”, CNRH (2007).

Não há, portanto, nenhuma incompatibilidade entre o processo de concessão do direito de lavra e a outorga do direito de uso da água, explorado mais adiante, nem tampouco óbice à caracterização e preenchimento dos requisitos do licenciamento ambiental das atividades de exploração da água mineral, com a expedição das respectivas licenças.

\section{A GESTÃo DAS ÁGUAS SUBTERRÂNEAS MEDIANTE OS INSTRUMENTOS DA PNRH}

\section{O processo de outorga dos direitos de uso da água}

A outorga do direito de uso dos recursos hídricos é o instrumento pelo qual o poder público atribui ao interessado, público ou privado, o direito de usar privativamente o recurso hídrico. Constitui um dos instrumentos da Política Nacional de Recursos Hídricos previstos na Lei no 9.433/97 e tem como objetivo assegurar o controle qualitativo e quantitativo dos usos da água e o efetivo exercício dos direitos de acesso à água. Assim se refere a legislação federal sobre o tema:

Art. $5^{\text {o }}$ São instrumentos da Política Nacional de Recursos Hídricos:

I. os Planos de Recursos Hídricos;

II. o enquadramento dos corpos de água em classes, segundo os usos preponderantes da água,

III. a outorga dos direitos de uso de recursos hídricos;

IV. a cobrança pelo uso de recursos hídricos;

V. a compensação a municípios (vetado);

VI. o Sistema de Informações sobre Recursos Hídricos. Brasil (1997).

O instrumento foi regulamentado através da Resolução CNRH nº 16/2001, a qual dispõe no seu artigo 4 ("Estão sujeitos à outorga"), "IV - extração de água de aqüífero subterrâneo para consumo final ou insumo de processo produtivo"), CNRH (2001b). 


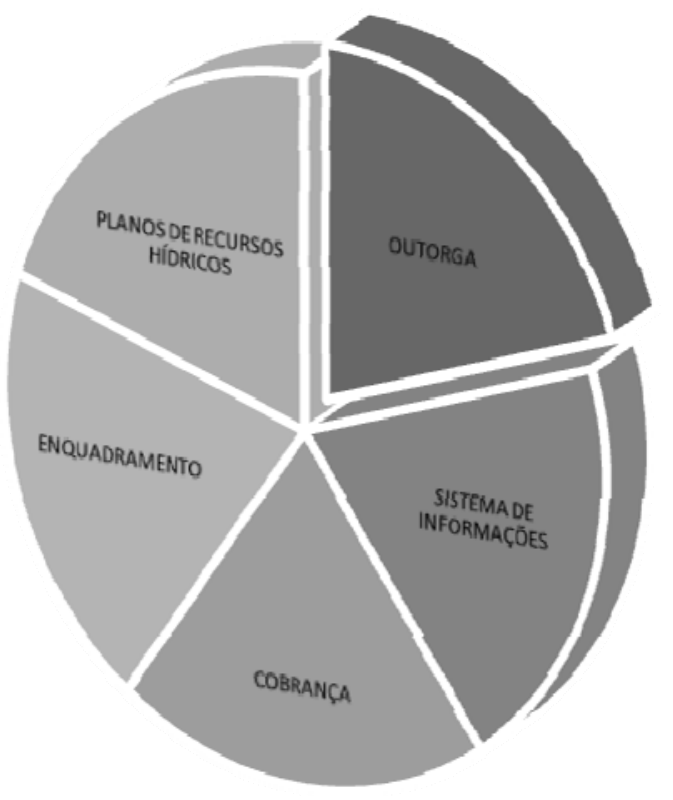

Figura 1 - Outorga nos instrumentos de gestão de recursos hídricos Fonte: Guimarães, 2010.

O instrumento da outorga é um mecanismo importante na garantia de sustentabilidade e proteção das águas subterrâneas, de modo que critérios para emissão da outorga deverão ser baseados em estudos sobre a disponibilidade hídrica subterrânea e a vulnerabilidade dos aquíferos à contaminação, entre outros. Nesse sentido, ressaltam-se os critérios concebidos e aplicados à Bacia Sedimentar Costeira Paraíba-Pernambuco inserida na Região do Baixo Curso do rio Paraíba, estado da Paraíba, por Costa et al. (2011).

Como se trata do instrumento que autoriza a exploração do recurso natural água dentro do sistema de gestão, a perspectiva da outorga enquanto peça-chave do sistema é evidenciada, sendo que, no momento autorizativo do uso da água bruta, é capaz de condensar aspectos do enquadramento dos corpos d'água, evidenciar objetivos definidos no Plano de Recursos Hídricos, possibilitar a cobrança pelo uso em termos técnicos mais justos e, finalmente, possibilitar o controle desejado pelo Sistema de Informações sobre recursos hídricos. (Figura 1). Discussão a cerca dos instrumentos de gestão, visualizados na Figura 1, com enfoque para as águas sub- terrâneas no contexto brasileiro é encontrada em Ribeiro et al. (2011).

No Brasil, a outorga das águas subterrâneas é de atribuição dos Estados da federação, mediante os órgãos estaduais de gestão. Em razão de a Constituição Federal definir as águas subterrâneas como bens de domínio estadual, os órgãos gestores nesse nível administrativo necessitam integração de procedimentos e informações, sob pena de o processo de gestão, especialmente o de águas subterrâneas restar ineficiente. A exploração deve ser feita mediante a emissão de outorga pelo órgão estadual competente, garantindo o uso equilibrado da água e observando os múltiplos usos do recurso natural.

Há uma Resolução do CNRH (a de $\mathrm{n}^{\mathrm{o}}$ 29/2002) específica para a atividade de mineração em geral, e entre suas deliberações destaca a necessidade de integração de procedimentos e articulada atuação entre órgãos e entidades cujas competências se refiram aos recursos hídricos, à mineração e ao meio ambiente e afirma que a atividade minerária tem especificidades de utilização e consumo de água passíveis de provocar alterações no regime dos corpos de água, na quantidade e na qualidade da água existente. Aponta a derivação ou captação de água 
superficial ou extração de água subterrânea, para consumo final ou insumo do processo produtivo; o lançamento de efluentes; e outros usos e interferências como formas de utilização de recursos hídricos relacionados à atividade minerária que estão sujeitas à outorga CNRH (2002a).

\section{O enquadramento das águas subterrâneas em classes e a integração institucional}

Existe uma relação direta entre o enquadramento dos corpos de água e o instrumento de outorga, em razão de dispositivos da Lei $\mathrm{n}^{\circ}$ 9.433/97, uma vez que a outorga (Art. 13) “(...) deverá respeitar a classe em que o corpo de água estiver enquadrado (...)”. Em função desse dispositivo, todas as análises de pedidos de outorga, seja de captação de água ou de lançamento de efluentes, deverão considerar as condições de qualidade estabelecidas pelas classes de enquadramento. Institucionalmente, cabe ao Comitê de Bacia Hidrográfica a responsabilidade pela aprovação da proposta de enquadramento dos corpos de água em classes de uso, para posterior encaminhamento ao respectivo Conselho de Recursos Hídricos Nacional ou Estadual, de acordo com o respectivo domínio dos corpos de água.

O enquadramento deve preceder a outorga, por razões técnicas evidenciadas pela necessidade de caracterizar o corpo hídrico do qual se está autorizando o uso - uma vez que se busca o estabelecimento do nível de qualidade (classe) a ser alcançado ou mantido em um segmento de corpo d'água ao longo do tempo. Objetiva-se "assegurar às águas qualidade compatível com os usos mais exigentes a que forem destinadas" e a "diminuir os custos de combate à poluição das águas, mediante ações preventivas permanentes" (Art. 9ํ) (Brasil, 1997). Seu significado enquanto instrumento de gestão de recursos hídricos extrapola o espaço de atuação da Política Nacional de Recursos Hídricos (PNRH), uma vez que representa elemento significativo da Política Nacional do Meio Ambiente (PNMA), a qual encontra-se disposta na lei federal no 6.938 (Brasil, 1981).

Sendo assim, no tocante ao foco da gestão integrada com os demais instrumentos de gestão ambiental, a Resolução no 357/2005 do CONAMA e a Resolução nº 396/2008, também do CONAMA, estabeleceram, sem prejuízo de outras que a sucederam, formalmente, a integração entre a PNMA e a PNRH no que se refere ao instrumento do enquadramento. A Resolução no $357 / 2005$ dedica-se ao enquadramento das águas superficais enquanto e a Resolução nº 396/2008 determina que "Art. $1^{\circ}$ Esta
Resolução dispõe sobre a classificação e diretrizes ambientais para o enquadramento, prevenção e controle da poluição das águas subterrâneas", CONAMA (2008). O sentido desta norma procura conjugar aspectos físicos relacionados às águas subterrâneas, como o fato de que "os aqüíferos se apresentam em diferentes contextos hidrogeológicos e podem ultrapassar os limites de bacias hidrográficas”, bem como o fato de que "as águas subterrâneas possuem características físicas, químicas e biológicas intrínsecas, com variações hidrogeoquímicas, sendo necessário que as suas classes de qualidade sejam pautadas nessas especificidades". A classificação objetiva, naturalmente, o estabelecimento de referências acerca dos aspectos intrínsecos que determinam sua qualidade e viabilizar o enquadramento em classes, CONAMA (2008).

Como aspecto relevante, a Resolução $\mathrm{n}^{\mathrm{o}}$ 396/2008 traduz expressamente a necessidade de gestão compartilhada das águas subterrâneas pelos órgãos tradicionais de gestão, colocados pela PNRH, pelos órgãos ambientais e pelos agentes de saúde, com vistas à prevenção de poluição e contaminação dos aquíferos (artigos 20, 21 e 22), CONAMA (2008). O artigo 20 da resolução trata de que "Os órgãos ambientais em conjunto com os órgãos gestores dos recursos hídricos deverão promover a implementação de Áreas de Proteção de Aqüíferos e Perímetros de Proteção de Poços de Abastecimento, objetivando a proteção da qualidade da água subterrânea”, CONAMA (2008). Ainda, no artigo 21, de que "Art. 21. Os órgãos ambientais, em conjunto com os órgãos gestores dos recursos hídricos e da saúde, deverão promover a implementação de Áreas de Restrição e Controle do Uso da Água Subterrânea, em caráter excepcional e temporário, quando, em função da condição da qualidade e quantidade da água subterrânea, houver a necessidade de restringir o uso ou a captação da água para proteção dos aqüíferos, da saúde humana e dos ecossistemas.”

Outro aspecto relevante é a consideração de que a "prevenção e controle da poluição estão diretamente relacionados aos usos e classes de qualidade de água exigidos para um determinado corpo hídrico subterrâneo" e que a promoção e proteção da qualidade das águas subterrâneas é um fato que merece cuidados extremos em razão de que os processos de recuperação são lentos e onerosos, CONAMA(2008).

No âmbito do CNRH, a Resolução nº 91 veio regulamentar os procedimento de enquadramento de águas superficiais e subterrâneas, procurando adotar uma postura compatível com a política de saneamento, segundo proposta na Lei $\mathrm{n}^{\mathrm{o}} 11.445$ 
de 2007 (Brasil, 2007). O artigo $3^{\circ}$, $§ 2^{\circ}$ da referida resolução impõe que o processo de enquadramento seja feito com participação ampla e discussão da comunidade da bacia hidrográfica, numa referência implícita ao Comitê de Bacia Hidrográfica. Relevante se faz observar que o enquadramento, por força do artigo 4º, VI, deverá considerar o "diagnóstico" feito com base em instrumentos técnicos como o mapeamento de áreas vulneráveis, a identificação de áreas reguladas por legislação específica, e o arcabouço legal e institucional pertinente, o que nos remete a uma perspectiva que favorece as modalidades de zoneamento. Idem para a carga potencial poluidora de "origem, urbana, industrial, agropecuária e de outras fontes causadoras de alteração”, CNRH (2008a).

O processo de definição dos critérios de enquadramento de águas doces envolve, portanto, o diagnóstico dos elementos do sistema ambiental em cada bacia hidrográfica, nos seus usos atuais e futuros, em uma abordagem que leve em conta as vocações econômicas e condicionantes sócio-ambientais dos usos não só das águas superficiais, como da água subterrânea.

No mesmo momento que surgiu a Resolução no 91, o CNRH emitiu a Resolução $n^{\circ} 92$ que busca estabelecer "critérios e procedimentos gerais para proteção e conservação das águas subterrâneas no território brasileiro", CNRH (2008b). Determinações diversas de caráter técnico são feitas, com base em estudos hidrogeológicos prévios, atribuições dos órgãos gestores e entes de bacia, no sentido da prevenção da degradação dos mananciais subterrâneos. Há destaque para as regiões costeiras de aquíferos, e determinações específicas sobre a recarga artificial de aquíferos.

A preocupação com a proteção das águas subterrâneas já havia sido materializada em 2002 na Resolução n⿳0 22/2002 do CNRH quando se afirma no seu artigo $5^{\mathrm{o}}$ que: "As ações potencialmente impactantes nas águas subterrâneas, bem como as ações de proteção e mitigação a serem empreendidas, devem ser diagnosticadas e previstas nos Planos de Recursos Hídricos, incluindo-se medidas emergenciais a serem adotadas em casos de contaminação e poluição acidental”, CNRH (2002b). Por força do Parágrafo Único do mesmo artigo, devem os diagnósticos para este fim, envolverem necessariamente a descrição e previsão da estimativa de pressões sócio-econômicas e ambientais sobre as disponibilidades, as estimativas das fontes pontuais e difusas de poluição, a avaliação das características e usos do solo; e a análise de outros impactos da atividade humana relacionadas às águas subterrâneas”, CNRH (2002b).

Deve ser destacada, ainda, no contexto da integração dos aspectos qualitativos e quantitativos das águas subterrâneas, a Resolução CNRH n ${ }^{\circ} 107$ que trata dos critérios para o estabelecimento da "Rede Nacional de Monitoramento Integrado Qualitativo e Quantitativo de Águas Subterrâneas." (CNRH, 2010). Tal Rede deverá ser planejada pela Agência Nacional de Águas (ANA) e implantada, operada e mantida pela Companhia de Pesquisa de Recursos Minerais (CPRM) em articulação com órgãos e entidades gestores de recursos hídricos.

\section{ATRIBUIÇÃO DE COMPETÊNCIAS E GESTÃO INTEGRADA DOS RECURSOS HÍDRICOS SUBTERRÂNEOS MINERAIS E NÃO-MINERAIS}

\section{As questões de dominialidade e gestão das águas superficiais e subterrâneas}

As principais questões a apresentarem desafios à gestão dos recursos hídricos subterrâneos estão concentradas nos aspectos da dominialidade e compatibilização entre os aspectos principiológicos dos sistemas de gestão e as peculiaridades do sistema federativo brasileiro, que envolve aspectos intrínsecos definidos constitucionalmente e que são embasadores da gestão pública no país.

Dentre outras questões, "a dominialidade de um bem determina a dimensão financeira, ou seja, determina a vinculação dos recursos arrecadados com a utilização destes bens, como o caso da cobrança pelo uso da água, a qual é caracterizada enquanto receita pública patrimonial, recolhida aos cofres públicos conforme a sua dominialidade" (Carvalho, 2007). Os sistemas naturais seguem lógicas próprias de funcionamento e os ciclos hidrológicos, em especial na sua porção subterrânea, não respeitam as regras colocadas pela sociedade para a sua organização espacial. A obediência ao Pacto Federativo, imposto pela Constituição Federal, se caracteriza pela noção de coisa pública, de respeito à autonomia dos entes estatais (Carvalho, 2007).

Uma vez o sistema ambiental tendo como características a interpenetração dos elementos do ciclo hidrológico em limites distintos daqueles colocados na superfície e além do conceito de bacia hidrográfica, mais relevo assume esta noção, para conformar os princípios da gestão no Brasil. 
É evidente a indissociação da consideração inclusiva de águas superficiais e subterrâneas na unidade de gestão. O mesmo acontece no subsolo, onde estão no mesmo limite territorial

Toda água que corre abaixo da superfície de uma determinada área - água do solo, água da zona não saturada, água da zona saturada, água de camadas aflorantes muito permeáveis (aqüífero livre), água de camadas encerradas entre outras relativamente menos permeáveis (aqüífero confinado), água de camadas relativamente argilosas (aquitardes), águas de camadas muito argilosas (aquicludes) Rebouças (2002, p. 124-125)

Assim, na consideração da bacia hidrográfica como unidade de gestão devem as águas subterrâneas estarem inclusas - independentemente de serem, no caso brasileiro, de domínio dos estados e de, em muitos casos, ultrapassarem os limites da respectiva bacia hidrográfica.

No caso da União Europeia, fez-se opção pela "Região Hidrográfica" como unidade para a gestão sendo interessante observar o disposto na Diretiva Quadro n ${ }^{\circ} 2000 / 60 / \mathrm{EU}$, art. $2^{\circ}, \mathrm{n}^{\circ} 15$, segundo a qual a região hidrográfica, mais extensa que a bacia hidrográfica é definida como "a área de terra e de mar constituída por uma ou mais bacias hidrográficas vizinhas e pelas águas subterrâneas e costeiras que lhes são associadas, definida (...) como a principal unidade para gestão das bacias hidrográficas"(European Union, 2000).

As águas minerais, não devem, por conseguinte, serem tratadas em apartado das demais, havendo necessidade de compatibilização entre a gestão das águas subterrâneas consideradas pela lei $\mathrm{n}^{\circ} 9.433 / 97$ e as mesmas.

\section{Delimitação espacial na exploração: zoneamento e áreas de proteção de aquíferos}

A delimitação de áreas de proteção de aquíferos ou de proteção de poços e de áreas de restrição e controle são procedimentos já conhecidos internacionalmente e em várias legislações que estabelecem diretrizes ambientais para o zoneamento $\mathrm{e}$ controle do uso e ocupação do solo, bem como para o controle da exploração da água subterrânea. Estas medidas visam proteger a qualidade da água captada contra poluição de várias naturezas ou a restrição de captação em casos de contaminação ou de sobreexploração. Os resíduos sólidos são potenciais contaminantes de fontes subterrâneas e os depósitos de lixo estão diretamente relacionados a essa contaminação, bem como o uso de substâncias nocivas e os despejos humanos. A água da chuva dissolve os resíduos acumulados e os carrega para o subsolo, tornando-se veículo de contaminação dos aquíferos.

Com a promulgação da Lei Federal $n^{\circ}$ 11.445, em 05 de janeiro de 2007, a lei de Diretrizes e Bases do Saneamento (Brasil, 2007), estabeleceram-se no Brasil as diretrizes nacionais para o saneamento básico trazendo consigo novo marco regulatório para o setor. Os serviços de saneamento básico no Brasil, portanto, compreendem: o abastecimento de água, o esgotamento sanitário, a coleta de lixo e a drenagem de águas pluviais. Todos estes serviços são essenciais à vida digna, e a qualidade da sua gestão provoca fortes impactos na saúde da população e no meio ambiente (Guimarães e Ribeiro, 2008). Em complemento desse regramento, em 2010 foi instituída a Política Nacional de Resíduos Sólidos (Lei Federal no 12.305, de 02 de agosto de 2010 - Brasil, 2010). Essas políticas possuem interferência direta na gestão das águas subterrâneas no contexto brasileiro.

A perfuração de poços sem perímetros de proteção e o licenciamento de empreendimentos potencialmente poluidores, podem gerar condições de violação da sustentabilidade hídrica local e regional. No Brasil, as empresas de exploração de águas minerais, devem apresentar a delimitação de suas áreas de proteção, em atendimento à Portaria DNPM no 231 de 31 de julho de 1998. Entretanto, há pouca ou nenhuma integração entre os diferentes órgãos federais, estaduais e municipais para que essa informação seja efetivamente utilizada no parcelamento do solo urbano, definição de zonas municipais de uso e ocupação do solo e no licenciamento de fontes potencialmente poluidoras nas áreas de alimentação e manutenção de águas subterrâneas.

No país, entretanto, o estabelecimento de perímetros de proteção de poços não é uma prática usual adotada pelas companhias de abastecimento e pelos demais usuários de águas subterrâneas. A prática é citada como comum nas legislações de países como a Alemanha, na qual o estabelecimento dessas restrições é considerado em caráter de proteção de saúde pública CETESB (2008). No tocante ao enquadramento de águas subterrâneas, como já discutido, há regulamentação específica contida na Resolução $\mathrm{n}^{-}$396/2008 do CONAMA, no sentido da necessidade do estabelecimento de zoneamentos para fins de conservação de águas subterrâneas (arts. 20, 21 e 22), CONAMA (2008). Idem para o CNRH (2008b). 


\section{Integração na gestão e o direito minerário}

A Resolução no 76, CNRH (2007), veio a estabelecer diretrizes gerais para a integração entre a gestão de recursos hídricos e a gestão de águas minerais, termais, gasosas, potáveis de mesa ou destinadas a fins balneários e representa um aspecto fundamental do tratamento integrado entre essas duas espécies de bens tutelados pelo direito e que, portanto, em razão da sua natureza jurídica diferenciada possuem necessidades específicas de gestão. $\mathrm{O}$ documento determina ao órgão gestor de recursos hídricos, no artigo $3^{\circ}$, a necessidade de tratar de forma integrada, do ponto de vista institucional, os aspectos informacionais da gestão:

Art. $3^{\circ} \mathrm{O}$ órgão gestor de recurso hídrico competente e o órgão gestor de recursos minerais, com vistas a facilitar o processo de integração, devem buscar o compartilhamento de informações e compatibilização de procedimentos, definindo de forma conjunta o conteúdo e os estudos técnicos necessários, consideradas as legislações específicas vigentes, CNRH (2007).

Essa integração, desse modo estabelecida formalmente, inclui parâmetros mínimos obrigatórios para aspectos específicos, a saber:

I. aos títulos de direitos minerários de pesquisa ou lavra de águas minerais, termais, gasosas, potáveis de mesa ou destinadas a fins balneários para a sua inclusão no Sistema de Informações de Recursos Hídricos e consideração pelos órgãos gestores de recursos hídricos;

II. aos atos administrativos relacionados ao uso de recursos hídricos, tais como: outorgas de direito de uso, manifestações prévias e autorizações de construção de poços, para a sua inclusão no sistema de informações de recursos minerais e consideração pelo órgão gestor de recursos minerais;

III. à área objeto de requerimento de pesquisa para água mineral, termal, gasosa, potável de mesa ou destinada a fins balneários;

IV. à área ou perímetro de proteção de fonte instituído pelo órgão gestor de recursos minerais, a fim de que seja considerado pelos órgãos gestores de recursos hídricos;

V. às áreas de restrição e controle estabelecidas pelo órgão gestor de recurso hídrico competente ou previstas nos planos de recursos hídricos, a fim de que sejam consideradas pelo órgão gestor de recursos minerais;

VI. ao monitoramento quantitativo e qualitativo disponível nos órgãos gestores;

VII. àquelas necessárias à formulação dos planos de recursos hídricos e à atuação dos comitês de bacias hidrográficas (Idem).

Essa resolução estabelece obrigações recíprocas aos respectivos órgãos gestores, de recursos hídricos e recursos minerais, que ao nível institucional representariam o cenário ideal baseado na disponibilidade de informações acerca da concessão de direitos minerários e da outorga do direito de uso da água doce.

Já a Portaria DNPM nº 231/1998 estabelece a metodologia de estudos necessários para a definição das áreas de proteção de fontes de água mineral, mas enxerga o aquífero apenas sob esse ponto de vista, desconsiderando as interações com as águas subterrâneas no sentido mais amplo.

\section{A INSTITUCIONALIZAÇÃO DAS ÁGUAS SUBTERRÂNEAS EM FACE DAS ÁGUAS MINERAIS: ASPECTOS DISTINTIVOS E PONTOS DE CONVERGÊNCIA}

A captação das águas subterrâneas no país é bastante relevante, seja nas regiões de maior oferta hídrica e clima mais ameno, seja no semiárido brasileiro, onde se torna fundamental para a sobrevivência de homens, fauna e flora. Entretanto, como assinala Rebouças (2009) "para abastecimento de médias e pequenas cidades é de até dez vezes mais barata, embora seja menos fotogênica. Não obstante, a falta de atuação dos órgãos responsáveis pelo controle das condições de uso e proteção das águas subterrâneas, nos níveis federal, estaduais ou municipais, faz com que o extrativismo ainda seja a forma dominante."

Um imperativo, do ponto de vista da condição de desenvolvimento sustentável da exploração de águas subterrâneas, tendo em vista a institucionalização diversa das águas subterrâneas e águas minerais é a sua consideração como importante commodity. As águas minerais possuem forte conteúdo econômico e impõe-se para a exploração sustentável o processo de integração com a gestão dos recursos hídricos, nos termos da Lei no 9.433/97. 
A exploração econômica do segmento água mineral é bastante expressiva, tendo apresentado volumes historicamente crescentes, justificando a necessidade da integração da exploração desse recurso natural com as estratégias de proteção ambiental adotadas no modelo brasileiro.

Dados da Associação Internacional de Águas Engarrafadas indicam que o Brasil ocupa o $4^{\circ}$ lugar no ranking mundial de produtores. Consome mais água engarrafada que países como Itália, Alemanha, França e Espanha. E fica atrás dos Estados Unidos, México (que crescem, em média, $8,5 \%$ ao ano) e da China, cuja demanda aumenta $17,5 \%$ a cada ano. A taxa média de crescimento mundial é de 7,6\% ao ano. Em 2007, por exemplo, foram consumidos 206 bilhões de litros de água vendida em garrafa. O mercado faturou cerca de US $\$ 100$ bilhões naquele ano (ABINAM, 2009).

Logo, a problemática da gestão integrada de recursos hídricos envolve instituições cujo enfoque pelo objeto de gestão pode produzir alguma controvérsia

Para o setor mineral e industrial, a água mineral é um recurso além de mineral, nobre e de qualidade superior às águas subterrâneas. Dessa forma, não pode fazer parte de uma gestão integrada de um recurso do qual não pertence - recurso hídrico. Os representantes dos órgãos de gestão, não concordam em caracterizar a água mineral como tão nobre que não possa participar da gestão integrada dos recursos hídricos. Segundo eles, todas as águas são nobres e por esse motivo é de fundamental importância, para o seu melhor aproveitamento, que participem da gestão integrada onde diversos setores da sociedade discutem o melhor uso da água. Caetano (2005, p.168)

Além desse aspecto, os órgãos de meio ambiente estaduais necessitam lidar com dados e elementos de regulação jurídica que, apesar de possuírem um objetivo comum, que é a proteção do meio ambiente, necessitam não raro de interpretação que permita compatibilização de procedimentos.

A visão segmentada de setores econômicos precisa ser trabalhada sob a forma de reforço regulatório e institucional, como forma de oferecer unidade ao processo de gestão de águas subterrâneas.

\section{CONCLUSÕES}

Existe satisfatória oferta de legislação no sentido de proporcionar tratamento regulatório ao uso e exploração dos recursos hídricos subterrâneos no Brasil, constante de leis federais, regulamentos e portarias de órgãos especializados conforme demonstrado ao longo deste artigo. Entretanto, na implantação das respectivas políticas de gestão, podem vir a surgir conflitos de interpretação e lacunas operacionais em razão de enfoques segmentados, especialmente por parte de setores usuários que realizem exploração comercial de água subterrânea. Um setor característico e expressivo economicamente está representado pelo produtor de água mineral, que também atende à regulamentos provenientes do DNPM e órgãos gestores ambientais.

Nos termos da Política Nacional de Recursos Hídricos, como elemento específico da política de gestão ambiental nacional, o tratamento integrado das águas subterrâneas e das águas minerais é um imperativo da gestão sustentável das águas subterrâneas, amparado pelo sistema jurídico pátrio nacional. A institucionalização da gestão de recursos hídricos, do exercício do direito minerário para extração de água e os aspectos ambientais merecem receber tratamento para a integração.

\section{AGRADECIMENTOS}

Esta pesquisa foi desenvolvida no âmbito do projeto "Integração dos instrumentos de outorga, enquadramento e cobrança para a gestão das águas subterrâneas" financiado pelo MCT/FINEP/CTHIDRO. As autoras agradecem às instituições mencionadas.

\section{REFERÊNCIAS}

ABINAM (2009) Associação Brasileira da Indústria de Águas Minerais. $O$ mercado de 7 bi de litros. Apud OEstadão. Obtido em http://www.abinam.com.br/lermais_ materias.php?cd_materias=71. Acesso em 10 de juIho. 2009.

ALBUQUERQUE, J. do P. T. (2007). Água subterrânea no Planeta Água. In: Estudos Geológicos v. 17 (1), Jun 2007, UFPE, Ed. Bagaço, 104 p., Semestral.

ALBuQueRQuE, J. do P. T. e RÊGO, J. C. (1998) Conceitos e definições para avaliação e gerenciamento conjunto de recursos hídricos superficiais e subterrâneos. Anais do IV Simpósio de Recursos Hídricos do Nordeste. Campina Grande: ABRH.

BRASIL (1945) Código de Águas Minerais. Lei federal $n^{0}$ 7.841, de 8 de agosto de 1945. 
(1967) Código de Mineração. Decreto-Lei $n^{0} 227$ de 28 de fevereiro de 1967.

(1981) Lei federal n6.938, de 31 de agosto de 1981. (1988) Constituição da República Federativa do Brasil. Brasília: Senado Federal.

(1997) Lei federal $n^{0}$ 9.433, de 08 de janeiro de 1997. (2007) Lei federal $n^{0} 11.445$, de 5 de janeiro de 2007. (2010) Lei federal $n^{0} 12.305$, de 2 de agosto de 2010.

CAETANO, L. C. (2005) A Política da Água Mineral: Uma Proposta de Integração para o Estado do Rio de Janeiro. Tese de Doutorado em Geociências. Campinas: Unicamp.

CETESB (2008) http://www.cetesb.sp.gov.br/Relatório de qualidade de águas em São Paulo. Gestão integrada de recursos hídricos. Anexo IV. p. 179-188.

CNRH (2001a) Resolução $n^{0} 15$, de 11 de janeiro. Estabelece diretrizes gerais para a gestão das águas subterrâneas. MMA. Brasília.

(2001b) Resolução n 16, de 08 de maio. Estabelece critérios gerais para a outorga de direitos de uso de recursos hídricos. MMA. Brasília.

(2002a) Resolução n² 29, de 11 de dezembro. Define diretrizes para a outorga de uso dos recursos hídricos para o aproveitamento dos recursos minerais. MMA. Brasília.

(2002b) Resolução n² 22, de 24 de maio. Estabelece diretrizes para inserção das águas subterrâneas nos planos de recursos hídricos. MMA. Brasília.

(2007) Resolução n 76, de 16 de outubro. Estabelece diretrizes gerais para a integração entre a gestão de recursos hídricos e a gestão de águas minerais, termais, gasosas, potáveis de mesa ou destinadas a fins balneários. MMA. Brasília.

(2008a) Resolução nº 91, de 05 de novembro. Dispõe sobre procedimentos gerais para o enquadramento dos corpos de água superficiais e subterrâneos. MMA. Brasília.

(2008b) Resolução nº 92, de 5 de novembro. Estabelece critérios e procedimentos gerais para proteção e conservação das águas subterrâneas no território brasileiro. MMA. Brasília.

(2010) Resolução no 107, de 13 de abril. Estabelece diretrizes e critérios a serem adotados para planejamento, implantação e operação de Rede Nacional de Monitoramento Integrado Qualitativo e Quantitativo de Águas Subterrâneas. MMA. Brasília.

CONAMA (2005) Resolução n 357, de 17 de março. Dispõe sobre a classificação dos corpos de água e diretrizes ambientais para 0 seu enquadramento, bem como estabelece as condições e padrões de lançamento de efluentes. MMA. Brasília.

(2008) Resolução n 396, de 03 de abril. Dispõe sobre a classificação e diretrizes ambientais para 0 enquadramento das águas subterrâneas. MMA. Brasília.

COSTA, M. L. M; RIBEIRO, M. M. R.; RÊGO, J. C.; ALBUQUERQUE, J. do P. T Proposição de critérios de outorga para águas subterrâneas. Revista Brasileira de Recursos Hídricos RBRH, v. 16, n. 1, p. 105-113, 2011.

DNPM (1997) Portaria n²22, de 28 de julho de 1997. (1998) Portaria $n^{0} 231$, de 31 de julho de 1998.

EUROPEAN UNION (2000) Directive of the European Parliament and of the Council establishing a framework for community action in the field of water policy. Directive 2000/60/EC, 2000.

GUIMARÃES, P. B. V. (2010) Avaliação de políticas públicas para a gestão integrada de recursos hídricos sob a ótica das dimensões institucional e ambiental. Tese (Doutorado em Recursos Naturais). Campina Grande: Universidade Federal de Campina Grande.

GUIMARÃES, P. B. V.; RIBEIRO, M. M. R. (2008) Uso eficiente da água nas cidades: a regulamentação do saneamento para sustentabilidade hídrica no Brasil. Anais do VIII Seminário Ibero-americano: Alterações Climáticas, Eficiência Energética, Operacionalidade e Segurança em Sistemas de Abastecimento e Drenagem Urbana. Lisboa.

REBOUÇAS, A. C. (2009) Desenvolvimento das águas subterrâneas no Brasil. Obtido em http://www.perfuradores.com.br/index.php?CAT=poc osagua\&SPG=info_cientificas\&SBPG=info_cientificas_tb\& STB=infocie_tb_30. Acesso em 5 de junho. 2009.

(2002) Águas subterrâneas. In: REBOUÇAS, A. C.; BRAGA, B.; TINDISI, J. G. (Orgs.). Águas Doces no Brasil. $2^{a}$ Ed. São Paulo: Escrituras.

RIBEIRO, M. M. R.; ALBUQUERQUE, J. P. T.; REGO, J. C.; GALVÃO, C. O.; CEBALLOS, B. S. O. (2011) Instrumentos de gestão das águas subterrâneas no contexto brasileiro. $8^{\circ}$ Seminário sobre Águas Subterrâneas. Lisboa: Associação Portuguesa de Recursos Hídricos.

\section{Distiction and Legal Aspects of Mineral Water and Groundwater in Brazil}

\section{ABSTRACT}

This paper performs a conceptual compilation to characterize and distinguish the legal and physical aspects of mineral water and groundwater. It explores controversial and distinctive points that can guide integrated water resource management from the institutional point of view. A review of literature and documents from Brazilian legal 
RBRH - Revista Brasileira de Recursos Hídricos Volume 17 n.2 - Abr/Jun 2012, 19 -29

texts was performed that distinguishes mineral and water rights. The research provides contributions to distinct elementary aspects and potential conflict and convergence points for the institutionalization of process effectiveness.

Key-words: Water rights, mineral water, groundwater. 